\title{
IDENTIFIKASI CITRA BATIK DENGAN METODE CONVOLUTIONAL NEURAL NETWORK
}

\author{
${ }^{1}$ Ayu Ratna Juwita, ${ }^{2}$ Tohirn Al Mudzakir, ${ }^{3}$ Adi Rizky Pratama, ${ }^{4}$ Purwani Husodo, ${ }^{5}$ Rahmat \\ Sulaiman
}

Teknik Informatika, FakultasTeknik dan Ilmu Komputer, Universitas Buana Perjuangan Karawang $^{1,2,3}$, Teknik Informatika, Stikom Elrahma ${ }^{4}$ Teknik Informatika, Institut Sains dan Bisnis Atma Luhur5.

ayurj@ubpkarawang.ac.id ${ }^{1}, \underline{\text { tohirin@ @ubpkarawang.ac.id }}^{2}, \underline{\text { adi.rizky@ubpkarawang.ac.id }}^{3}$, purwanihusodo@ gmail.com ${ }^{4}$, rahmatsulaiman @atmaluhur.ac.id $^{5}$

\begin{abstract}
ABSTRAK
Batik merupakan suatu kerjianan tangan yang memiliki nilai seni yang cukup tinggi dan juga salah satu bagian dari budaya indonessia. Untuk melestraikan budaya warisan batik dapat dikakukan dengan berbagai cara dengan pengenalan pola batik yang sangat beragam khususnya batik karawang. Penelitian ini membahas klasifikasi pola batik karawang menggunakan Convolutional Neural Network (CNN) dengan ciri gray level Co-ocurrence Matrix. Proses awal yang akan dilakukan yaitu preprocessing untuk mengubah citra warna menjadi grayscale, selanjutnya citra akan di segmentasikan sehingga memisahkan citra pola batik dengan background menggunakan metode otsu dan di ekstraksi menggunakan metode gray level co-ocurrence matrix untuk mendeteksi pola-pola batik. selanjutnya akan diklasifikasikan menggunakan metode Convolutional Neural Network (CNN) yang memberikan hasil klasifikasi citra batik. Dengan penerapan model klasifikasi citra batik Karawang ini memliki data training sebanyak 1094 citra latih dengan nilai akurasi $18,19 \%$ untuk citra latih, citra dapat mengklasifikasikan dengan uji coba 344 citra batik, 45 citra batik Karawang, 299 citra batik luar Karawang mencapai 18,60\% nilai tingkat akurasi, sedangkan hasil uji coba menggunakan citra batik karawang yang dapat dikenali dan diklasifikasikan mencapai nilai tingkat akurasi 73,33\%.
\end{abstract}

Kata Kunci : Klasifikasi citra batik, CNN, GLCM, Otsu, Image Processing

\section{ABSTRACT}

Batik is a handicraft that has a high artistic value and also Batik is a part of Indonesian culture. To preserve the cultural heritage of batik it can be do in various ways with the introduction of many diverse batik patterns, especially karawang batik.. This study discusses the classification of Karawang batik patterns using Convolutional Neural Network (CNN) with gray level co-occurrence matrix characteristics. Initial process is preprocessing to convert the color image to grayscale, Then the image will be segmented. It can separated the image of the batik pattern from the background using the Otsu method and extracted using the gray level co-occurrence matrix method to detect batik patterns. Then, it will be classified using the Convolutional Neural Network (CNN) method which gives the results of batik image classification. With the application of this Karawang batik image classification model, it has training data of 1094 training images with an accuracy value of 18.19\% for training images, images can be classified by testing 344 batik images, 45 Karawang batik images, 299 outer Karawang batik images reaching $18.60 \%$ the value of the accuracy level, while the results of the trial using the image of batik karawang which can be recognized and classified reach an accuracy level of $73.33 \%$.

Keywords: Batik image classification, CNN, GLCM, Otsu, Image Processing 
Ayu Ratna Juwita, Tohirin Al Mudzakir, Adi Rizky Pratama, Purwani Husodo, Rahmat

Sulaiman

Vol 6 No 1

ISSN : 2541-6995

E ISSN : 2580-5517

\section{PENDAHULUAN}

Indonesia merupakan satu dari banyak negara di dunia yang memiliki berbagai macam ragam budaya. Kebudayaan di Indonesia tersebar pada seluruh aspek kehidupan masyarakat, salah satu hasil seni budaya Indonesia yaitu batik yang merupakan warisan budaya yang sudah diakui UNESCO pada tanggal 02 oktober 2009 dan memiliki berbagai macam jenis motif serta ciri khas sesuai daerah asalnya. Motif batik adalah kerangka bergambar yang mewujudkan batik secara keseluruhan. Motif batik dapat disebut juga corak atau pola batik (Arisandi, Suciati, and Wijaya 2011) . Motif dan ragam hias batik lahir dan dibangun dari proses kognitif manusia yang didapat dari alam dan sekitarnya. Hal ini dianggap sebagai suatu aspek yang menarik untuk diteliti dan dikembangkan dengan sains dan teknologi (Mulaab 2010).

Batik Karawang merupakan salah satu jenis batik di Indonesia dan telah mengalami perkembangan yang cukup baik, serta merupakan salah satu ciri khas masyarakat daerah Kabupaten Karawang. Batik Karawang merupakan seni budaya baruwalau terdapat sejarah pada saat dahulu, meskipun dalam rentang waktu yang lama batik Karawang tidak lagi hidup dan hanya sebatas nama. Tahun 2011 batik karawang kembali hidup dengan adanya masyarakat yang masih peduli terhadap kelestariannya. Maka dari itu diperlukan suatu kegiatan untuk melestarikan, mengembangkan dan mengenalkan motif batik Karawang (Kuswoyo 2015). Batik Karawang pertama kali dibuat pada tahun 1928 sebagai alas meja peribadatan yang biasa digunakan oleh penganut agama Budha yang disebut Tok Wi, tetapi baru dikembangkan dan diproduksi pada tahun 2008. Adapun perkembangannya tidakseperti batik-batik di daerah Jawa Tengah yang sangat dikenal baik oleh masyarakat lokal, luar daerah bahkan internasional seperti batik Trusmi, Pekalongan, Solo atau Yogyakarta, karena sampai saat ini masih banyak orang yang belum mengenal batik Karawang (Triana and Retnosary 2020).

Beberapa peniltian mengenai citra batik yang pernah dilakukan (Mawan 2020) Klasifikasi mennggunakan metode CNN termasuk dalam jenis deep neural network karena dalamnya tingkat jaringan dan banyak diimplementasikan dalam data citra. (Arrofiqoh and Harintaka 2018) menerapkan algoritma CNN untuk membedakan jenis tanaman dengan memberikan label semantik dari objek jenis tanaman. (Bariyah, Rasyidi, and Ngatini 2021) menjelaskan teantang CNN merupakan salah satu algoritma deep learning pengembangan multi-layer perceptron (MLP) yang telah banyak digunakan dalam klasifikasi data, khususnya klasifikasi citra. CNN terdiri dari satu atau lebih lapisan konvolutional, seringnya dengan sauatu lapisan 
Ayu Ratna Juwita, Tohirin Al Mudzakir, Adi Rizky Pratama, Purwani Husodo, Rahmat

Sulaiman

Vol 6 No 1

ISSN : 2541-6995

E ISSN : 2580-5517

subsampling yang diikuti oleh satu atau lebih lapisan yang terhubung penuh sebagai standar jaringan syaraf. Dalam prosesnya CNN akan melakukan training dan testing terhdap batik Riau sehingga dapat dikumpulkan model batik yang terklasifikasi berdasarkan ciri khas yang ada pada batik Riau sehingga dapat ditentukan gambar (image) yang merupakan gambar batik Riau dan yang bukan merupakan batik Riau (Fonda 2020). Penelitian ini penerapan model klasifikasi citra batik Karawang ini dapat menghasilkan nilai akurasi mencapai 80\% tingkat akurasi, hasil nilai rata-rata dari presisi mencapai $91 \%$ sedangkan hasil nilai rata-rata dari recall mencapai 83\%. dengan uji coba 50 citra batik, 40 citra batik Karawang, 10 citra batik luar Karawang.(Juwita and Solichin 2018).

\section{METODE PENELITIAN}

Dalam metode penelitian ini menjelaskan model bagaimana mengimplementasikan metode Convolutional Neural Network (CNN) untuk mengklasifikasikan citra batik dengan ciri gray level co-occurrence matrix. Sumber dan jenis data yang digunakan dalam pengumpulan data dengan menganalisis pola motif batik karawang.

Subjek dalam penelitian ini yaitu membuat sebuah model untuk mengklasifikasikan pengenalan pola motif batik karawang menggunakan pengolahan citra. Model pengenalan ciri batik karawang menggunakan metode Convolutional Neural Network (CNN) dengan beberapa tahap. Langkah pertatama yaitu pemprosesan terhadap citra awal yang disebut dengan (preprocessing) bertujuan untuk menyiapkan peningkatan kualias citra awal sebelum diolah menjadi grayscle. Langkah selanjutnya proses segmentasi citra dengan melakukan thresholding menggunakan otsu. Pada tahap Ekstraksi fitur dengan ciri nilai gray level cooccurrence matrix untuk menentukan ciri pola batik pada tahapan ini bertujuan untuk mendeteksi area pola motif batik, hasil nilai ekstraksi digunakan sebagai nilai inputan untuk diklasifikasikan menggunakan Convolutional Neural Network (CNN).

Langkah-langkah penelitian dilakukan secara bertahap agar mendapatkan hasil dari permasalahan. Berikut alur langkah-langkah penelitian: 
Ayu Ratna Juwita, Tohirin Al Mudzakir, Adi Rizky Pratama, Purwani Husodo, Rahmat

Sulaiman

Vol 6 No 1

ISSN : 2541-6995

E ISSN : 2580-5517

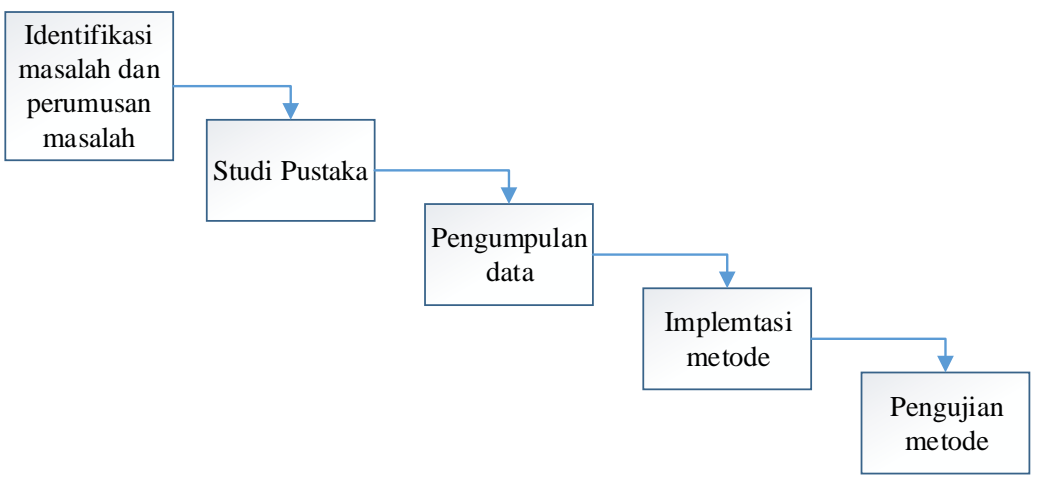

Gambar 1. Langkah-langkah penelitian

1. Identikasi Masalah dan Perumusan masalah

permasalahan yang dapat diselesaikan dalam penelitian ini yaitu identifikasi citra batik untuk mengklasifikasikan citra batik berdasarkan bentuk dan motifnya.

2. Studi Pustaka

Pustaka yang dijadikan dalam penelitian ini yaitu referensi buku, jurnal ilmiah yang mendukung. Kajian Pustaka dalam penelitian ini yang terkait yaitu delam penggunaan fitur ekstraksi yang dapat dihitung berdasarkan nilai cirinya menggunakan gray level cooccurrence matrix dan penggunaan Convolutional Neural Network dalam permasalahan klasifikasi citra batik.

3. Pengumpulan data

Pengumpulan data dapat diperoleh melalui sumber data primer. Data primer berupa foto pola batik yang diambil menggunakan kamera, sumber data primer didapat dari Bale Batik Taza Karawang. Teknik pengumpulan data dilakukan menggunakan studi kepustakaan, teknik pengumpulan data tersebut dilakukan dengan cara mempelajari literatur-literatur, dan jurnal-jurnal penelitian yang berkaitan dengan permasalahan yang dibahas. Data terdiri dari 15 citra foto macam-macam motif batik.

4. Implementasi Metode

Model untuk menyelesaikan masalah dengan memanfaatkan pengolahan citra dengan mengklasifikasikan citra batik sebagai berikut : 
Ayu Ratna Juwita, Tohirin Al Mudzakir, Adi Rizky Pratama, Purwani Husodo, Rahmat

Sulaiman

Vol 6 No 1

ISSN : 2541-6995

E ISSN : 2580-5517

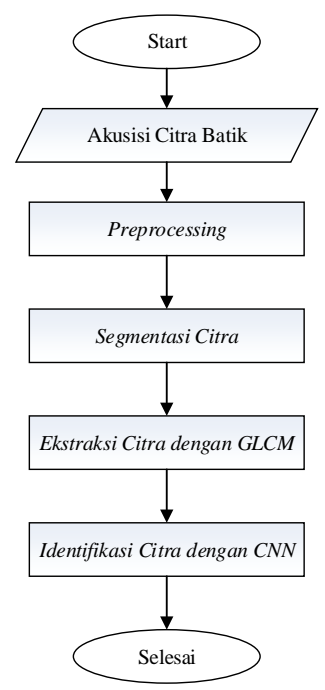

Gambar 2. Pendekatan Komputasi untuk Identifikasi Citra Batik

a. Akusisi Citra Batik

Mengumpulkan citra batik dari beberapa jenis pola motif batik daerah Karawang dan setiap citra pola batik disimpan pada file dengan format gambar *jpg.

b. Preprocessing

Proses pada tahapan prepocessing dilakakukan dengan cara pengambilan sample pada bagian tertentu dari obyek pola batik. Selanjutnya akan dilakukan perubahan warna dari citra RGB menjadi grayscle.

Untuk mendapatkan citra graycsle (keabuan) menggunakan rumus :

$$
\mathrm{I}(\mathrm{x}, \mathrm{y})=\alpha \cdot R+\beta \cdot G+\gamma \cdot B
$$


Ayu Ratna Juwita, Tohirin Al Mudzakir, Adi Rizky Pratama, Purwani Husodo, Rahmat

Sulaiman

Vol 6 No 1

ISSN : 2541-6995

E ISSN : 2580-5517

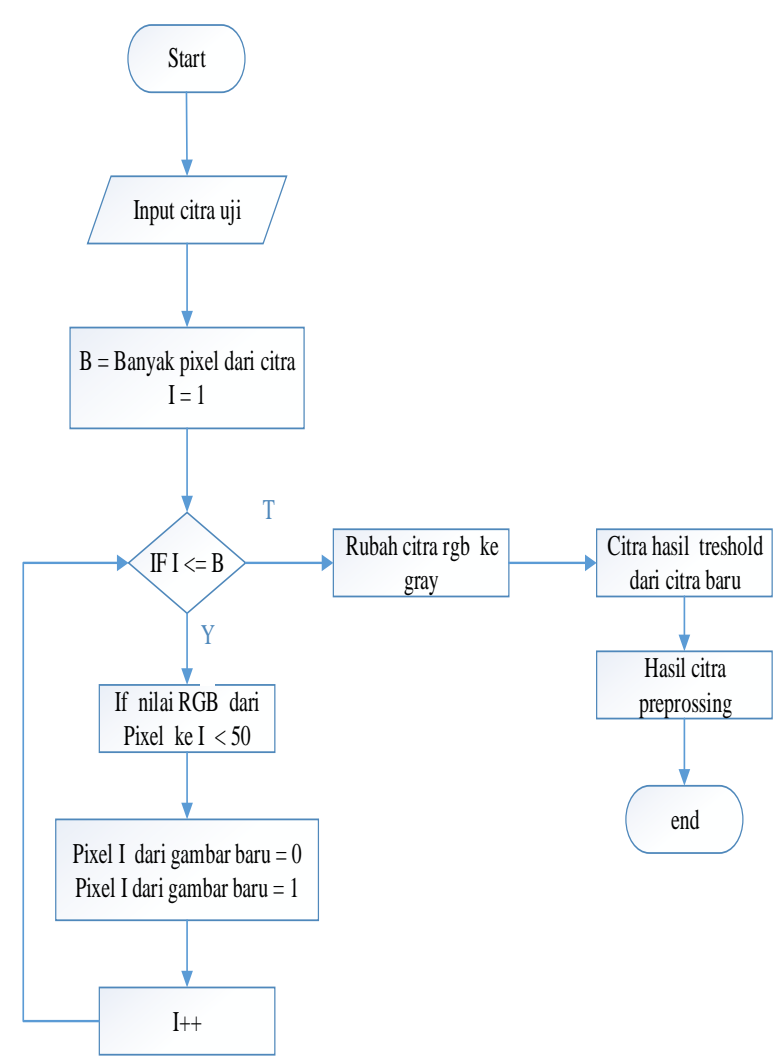

Gambar 3. Alur proses prepocessing

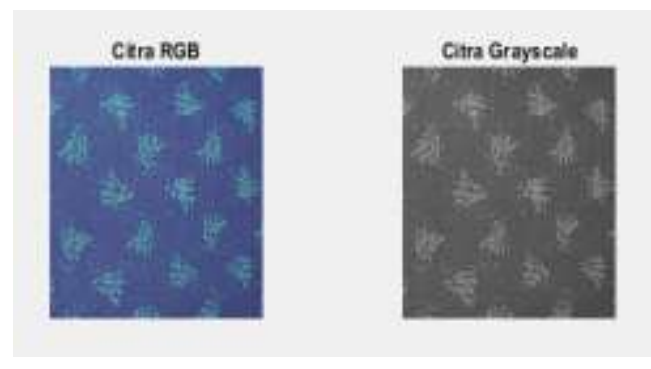

Gambar 4. Citra RGB ke Citra Grayscale (Hasil Preoocessing)

c. Segmentasi Citra

Segmentasi citra dilakukan menggunakan citra dengan tresholding otsu. Hal ini untuk memisahkan antara obyek pola dengan background. Formulasi dari metode otsu adalah sebagai berikut : Pertama-tama, probabilitas nilai intensitas i dalam histogram dihitung melalui :

$P(i)=\frac{n_{i}}{N}, p(i) \geq 0, \sum_{1}^{256} p(i)=1$

Ket :

P : Probabilitas

$i$ : nilai intensitas

$n_{i}:$ Jumlah piksel berintensitas

N : Jumlah Semua Piksel 


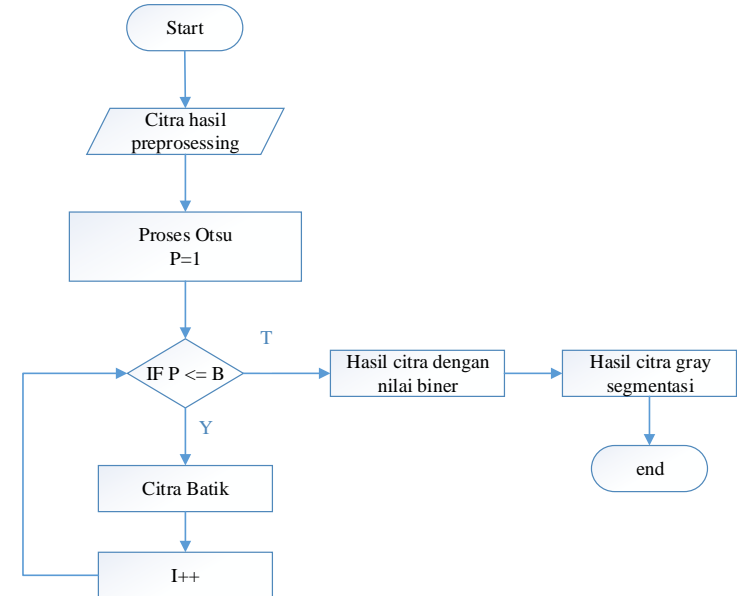

Gambar 5. Alur proses segmentasi otsu

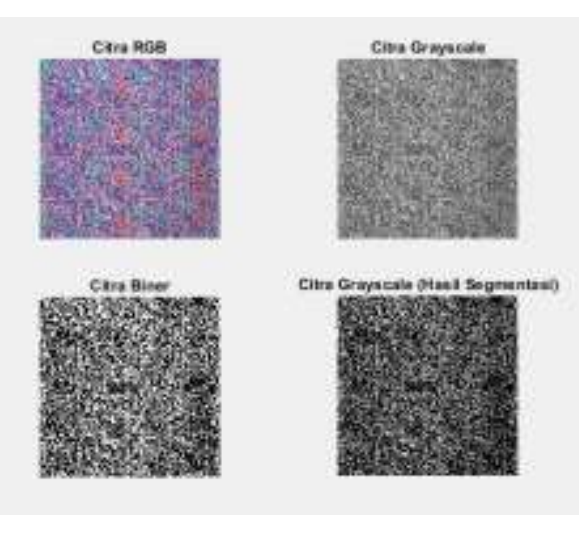

Gambar 6. Citra hasil segmentasi dengan otsu

\section{d. Ektraksi Citra dengan GLCM}

Ektraksi citra menggunakan ciri Gray Level Co-Occurrence Matrix (GLCM) bertujuan untuk mendeteksi area pola motif batik, untuk menentukan ciri fitur ekstraksi dengan GLCM, yaitu dengan nilai Contrast, Energy, Homogeneity, Correlation.

1. contrast $=\sum_{a, b} P_{a, b}(a-b)^{2}$

2. Energy $=\sum_{a, b} P_{\emptyset, d}^{2}(a-b)$

3. homogenitas $=\sum_{a} \sum_{b} \frac{1}{1+(a-b)^{2}} P_{\emptyset, d}(\mathrm{a}, \mathrm{b})$

4. Korelasi $=\frac{\sum_{a, b}\left[(a b) P_{\emptyset, d(a, b)-\mu_{x} \mu_{y}}\right.}{\sigma_{x} \sigma_{y}}$

Tahap pembentukan GLCM dengan arah $0^{0}$ dan jarak $\mathrm{d}=1$ maka ditentukan koordinat arah $(\mathrm{x}, \mathrm{y})$ yaitu $(1,0)$. Setelah arah ditentukan selanjutnya dibentuk matriks kookurensi dengan cara menghitung frekuensi kemunculan pasangan nilai keabuan antar piksel pada jarak dan arah yang telah ditentukan.

e. klasifikasi Citra

Convolutional Neural Network (CNN) menjadi tahap terakhir untuk pengklasifikasian dalam mengidentifikasi citra batik karawang. Metode CNN merupakan jenis Deep Learning yang sering digunakan dalam mengklasifikasikan data citra. Neuron pada CNN di presentasikan ke dalam bentuk 2 dimensi, perbedaannya terletak pada operasi linear dan parameter bobotnya. Proses ekstraksi CNN itu sendiri berupa lapisan tersembunyi (hidden layer) antara lain lapisan konvolusi, pooling dan ReLU (fungsi 
Ayu Ratna Juwita, Tohirin Al Mudzakir, Adi Rizky Pratama, Purwani Husodo, Rahmat

Sulaiman

Vol 6 No 1

ISSN : 2541-6995

E ISSN : 2580-5517

aktifasi). Adapun arsitektur menggunakan metode $\mathrm{CNN}$ terlihat seperti pada Gambar 7 dibawah ini.

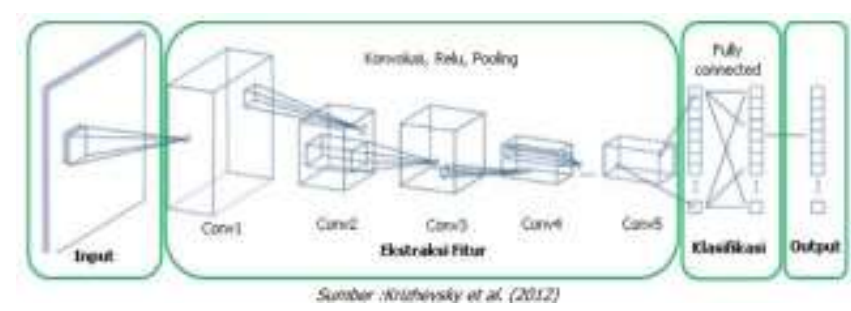

Gambar 7. Arsitektur CNN

\section{Lapisan Konvolusi}

Operasi konvolusi ini bertujuan untuk mendeteksi karakter dari suatu objek seperti tepi, kurva atau warna. Beberapa parameter pada lapisan ini dapat diubah untuk dimodifikasi sifat pada tiap lapisan seperti ukuran filter, stride dan padding. Proses stride dan padding dapat diilustrasikan seperti pada Gambar 8.

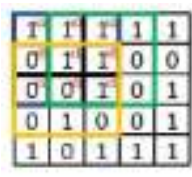

(a)

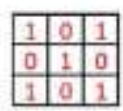

(b)

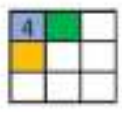

(c)

Gambar 8. Operasi konvolusi dengan stride 1 (a) Input data 5x5 (b) filter 3x3 (c) bidang receptive $3 \times 3$

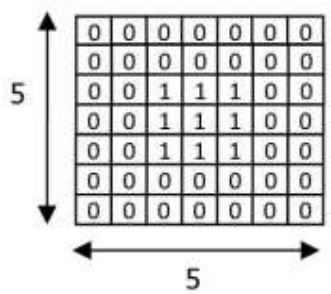

Gambar 9. Operasi zero padding 2 pada data $3 \times 3$

Tiga keuntungan dari proses konvolusi yaitu,

1. Dapat mereduksi parameter yang ada dengan mekanisme berbagi bobot (weigh sharing) pada peta fitur yang sama

2. Korelasi antar pixel dapat di pelajari menggunakan konektivitas lokal

3. Invarian ke lokasi objek tertentu

\section{Aktifasi ReLU}

Fungsi aktivasi ReLU adalah $\mathbf{f}(\mathbf{x})=\max (\mathbf{0 , x})$. Nilai output neuron dapat dinyatakan $\mathrm{s}$ 0 jika inputnya negatif. ReLU (Rectification Linear Unit) adalah suatu operasi untuk 
Ayu Ratna Juwita, Tohirin Al Mudzakir, Adi Rizky Pratama, Purwani Husodo, Rahmat

Sulaiman

Vol 6 No 1

ISSN : 2541-6995

E ISSN : 2580-5517

mengenalkan nonlinearitas dalam meningkatkan representasi model. Jika nilai input adalah positif, maka output dari neuron adalah nilai input aktivasi itu sendiri.

\section{Pooling}

Pooling atau subsampling dipergunakan untuk pengurangan ukuran matriks. Ada dua pooling yaitu average pooling dan max pooling. Strategi yang sering di pakai pada lapisan ini adalah max pooling. Nilai yang diambil pada average pooling adalah nilai rata-rata sedangkan nilai yang diambil dari max pooling adalah nilai maksimal. Berikut perhitungan pada max-pooling seperti pada Gambar 10.

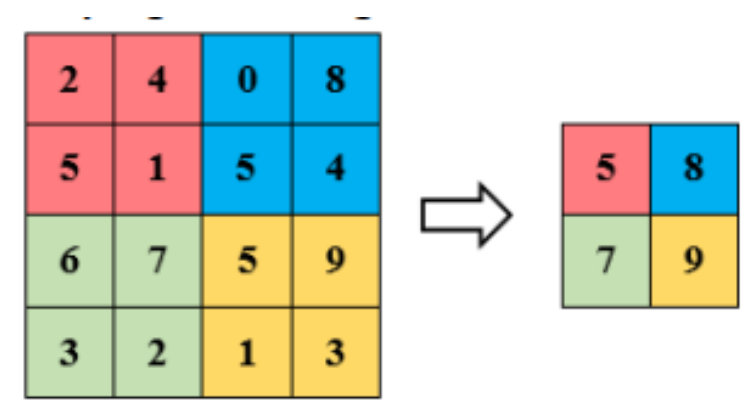

Gambar 10. Perhitungan max-pooling

Output dari lapisan di bagi atas beberpa grid kecil, selanjutnya mengambil nilai terbesar dari setiap grid, sehingga akan terbentuk sebuah matrik baru setelah mengalami reduksi. (Arrofiqoh and Harintaka 2018)

\section{Pengujian Metode}

Hasil pengujian dihitung dengan Nilai Accuracy didapat dari seluruh jumlah true positive (TP) dibagi dengan banyaknya data atau penjumlahan dari seluruh nilai pada kolom tabel dapat di gambarkan dengan persamaan berikut

$$
\text { Accuracy }=\frac{T P(1)+T P(2)+T P(3)+T P(4)+\cdots+T P(9)}{N}
$$

\section{HASIL PENELITIAN}

Hasil penerapan model metode Convolutional Neural Network (CNN) untuk mengidentifikasikan citra batik karawang dengan cara melakukan pelatihan citra, uji coba citra dan pengolahan citra agar mendapatkan hasil dari nilai akurasi klasifikasi citra batik.

\section{Tabel 1. Akusisi Citra}




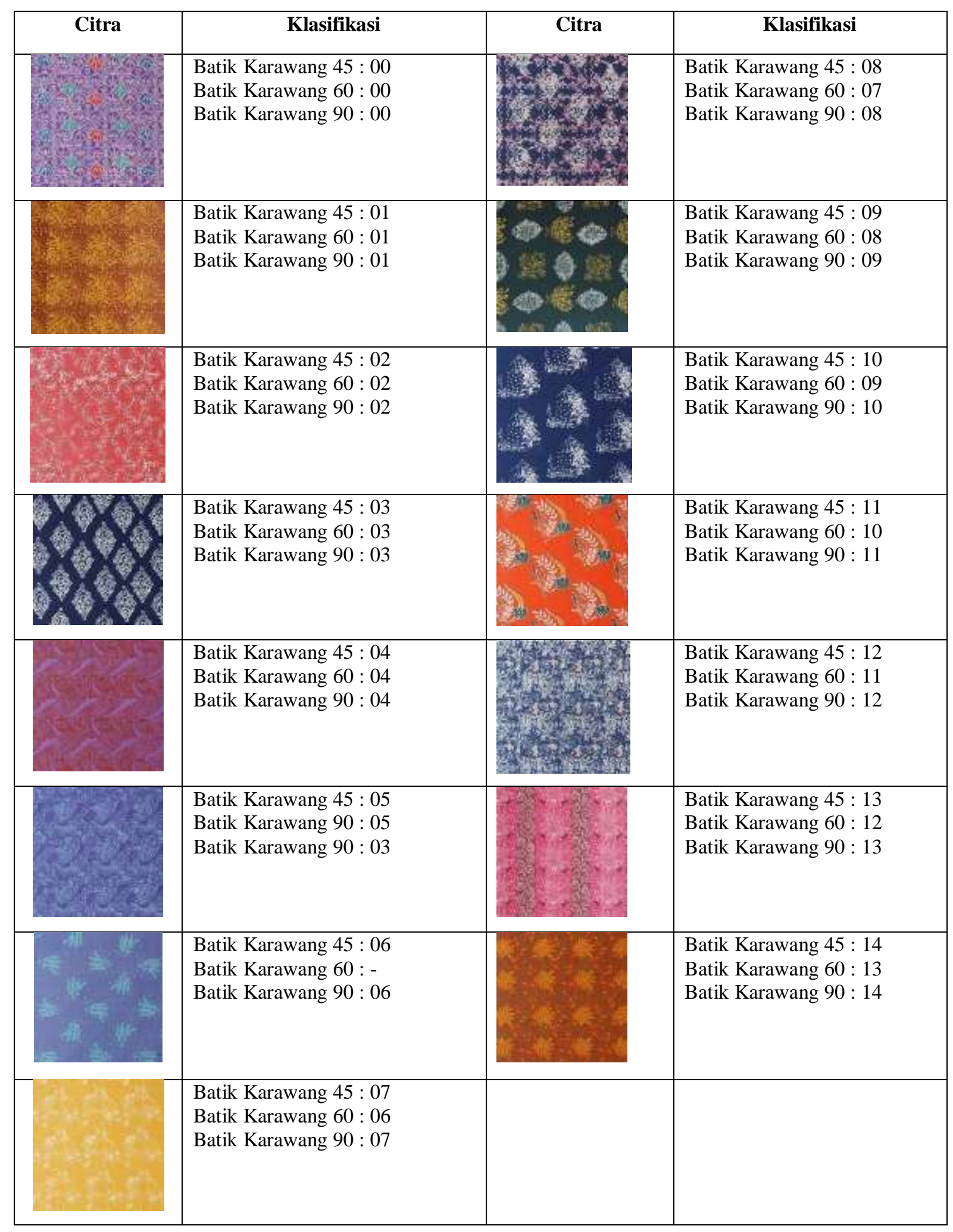

\section{Proses Training Citra}


Ayu Ratna Juwita, Tohirin Al Mudzakir, Adi Rizky Pratama, Purwani Husodo, Rahmat

Sulaiman

Vol 6 No 1

ISSN : 2541-6995

E ISSN : 2580-5517

Sebelum melakukan uji coba terhadap citra batik dilakukan training citra batik terlebih dahulu agar dapat mengidentifikasi citra saat melakukan uji coba saat mengklasifikasikan citra batik karawang, proses training ini melalui beberapa tahap yang dijelaskan pada alur gambar 10 .

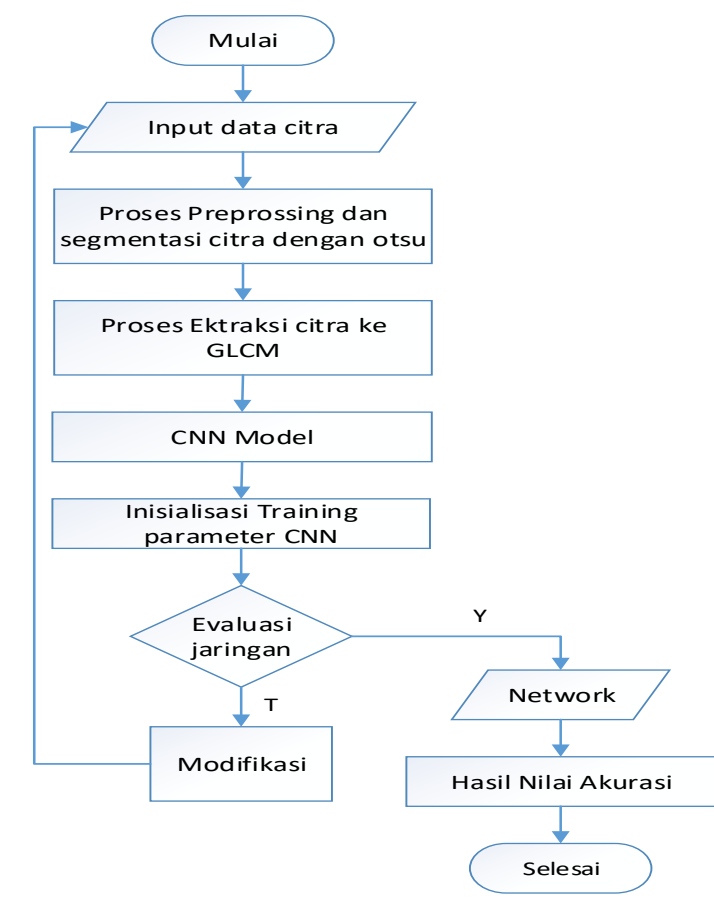

Gambar 11. Alur proses pelatihan citra batik

Hasil dari proses training menggunakan mottode Convolutional Neural Network (CNN) sebagai berikut :

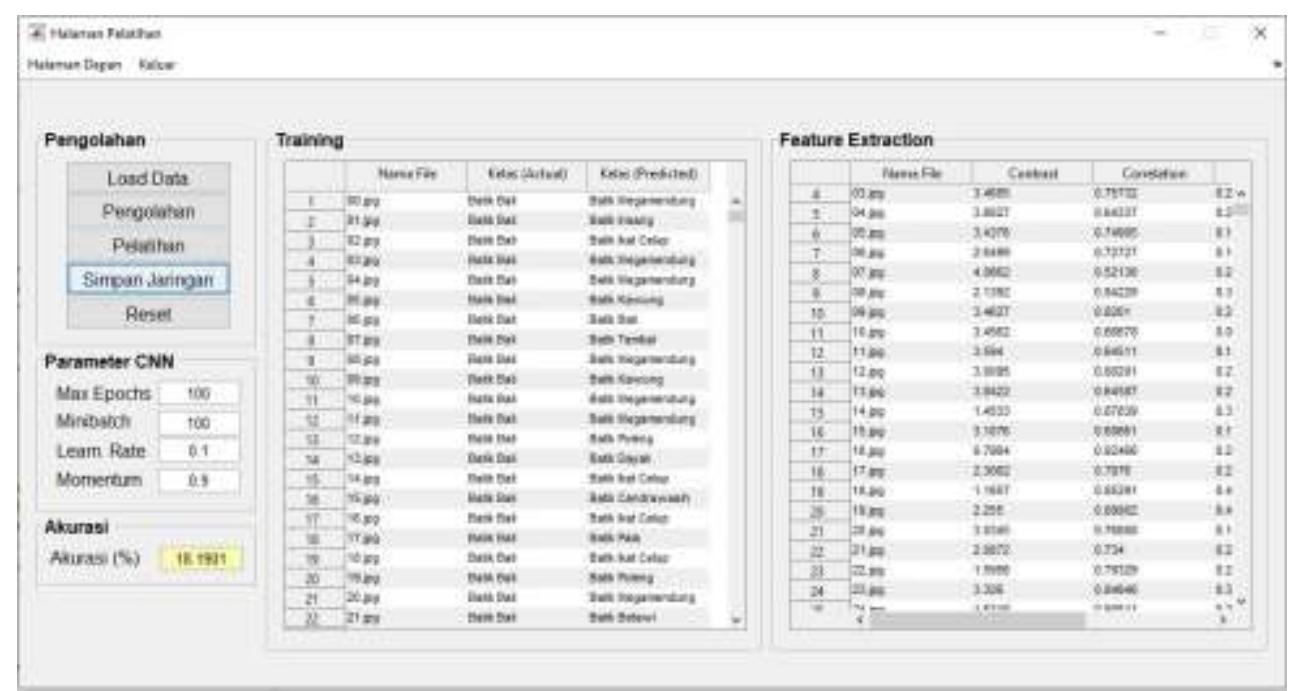

Gambar 12. Tampilan GUI saat melakukan training data citra 
Ayu Ratna Juwita, Tohirin Al Mudzakir, Adi Rizky Pratama, Purwani Husodo, Rahmat

Sulaiman

Vol 6 No 1

ISSN : 2541-6995

E ISSN : 2580-5517

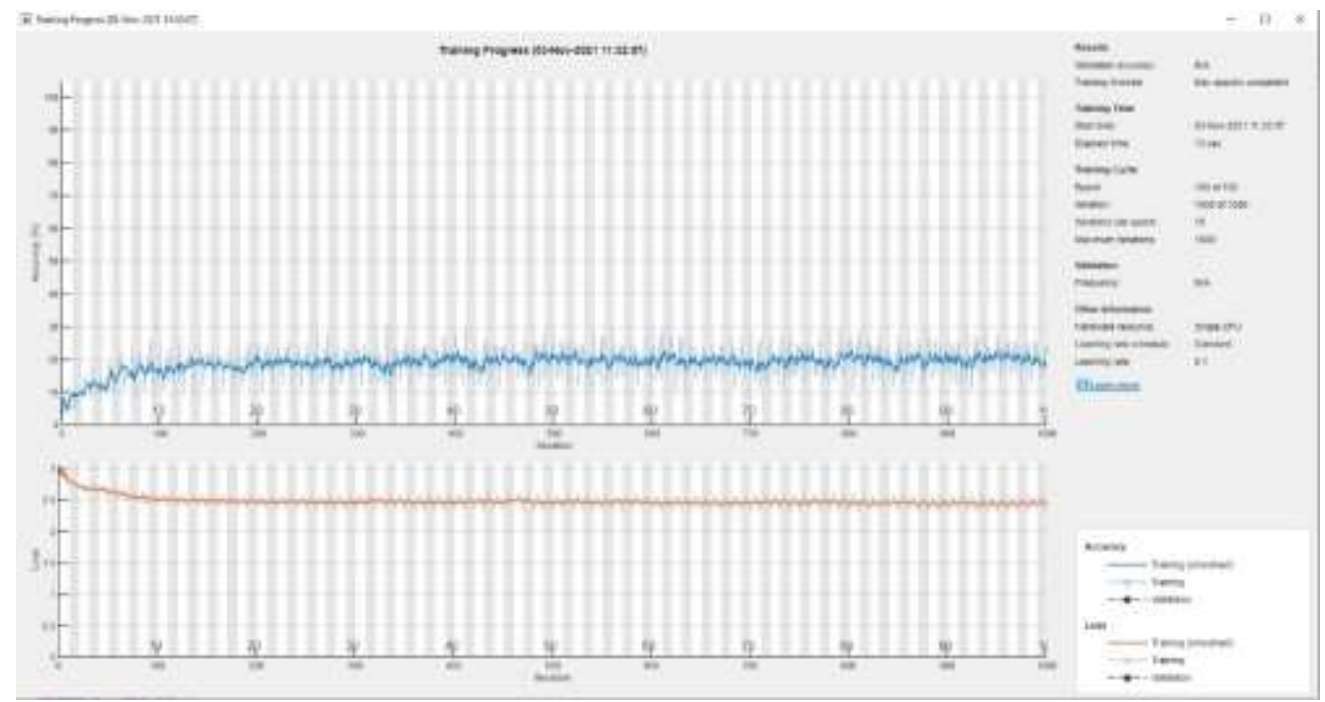

Gambar 13. Proses Trainning dengan CNN

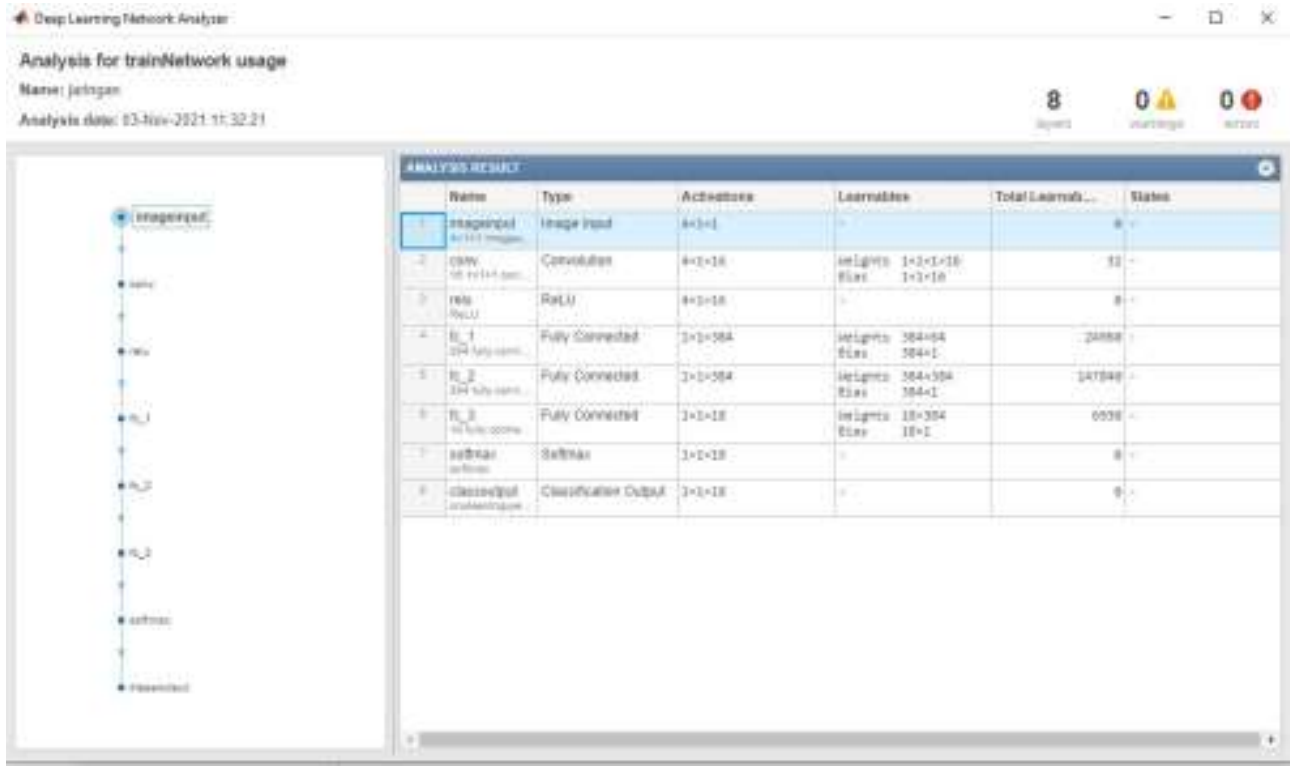

Gambar 14. Hasil Analysis Training CNN

\section{Proses Uji Citra}

Setelah melakukan proses training citra batik dilakukan pengujian citra batik untuk mengidentifikasi citra batik, dengan melalui alur proses sebagai berikut : 
Ayu Ratna Juwita, Tohirin Al Mudzakir, Adi Rizky Pratama, Purwani Husodo, Rahmat

Sulaiman

Vol 6 No 1

ISSN : 2541-6995

E ISSN : 2580-5517

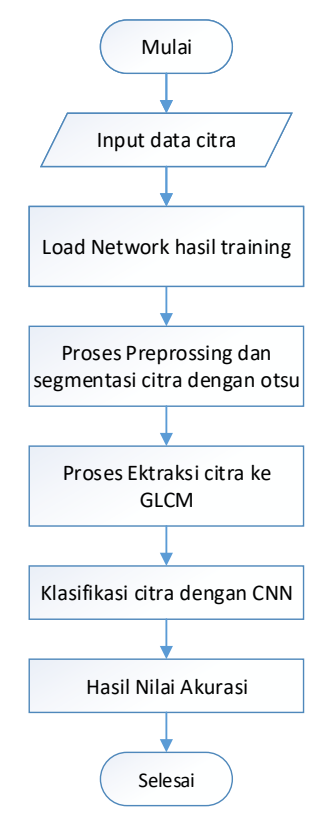

Gambar 15. Alur proses Uji Citra Batik

Hasil dari proses pengujian citra menggunakan mottode Convolutional Neural Network $(\mathrm{CNN})$ sebagai berikut :

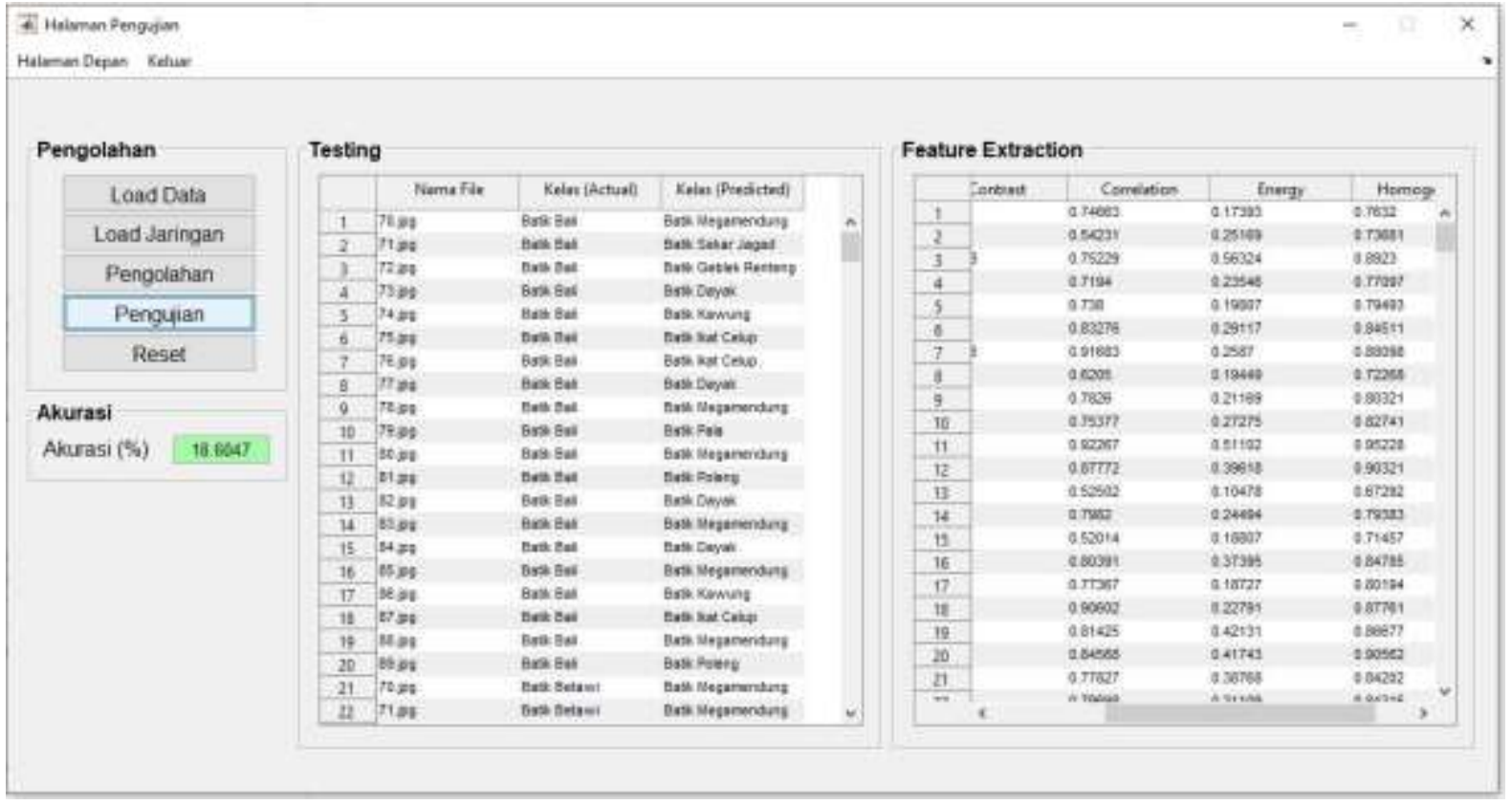

Gambar 16. Tampilan GUI saat melakukan pengujian data citra batik

Hasil dari pengujian citra dengan data uji sebanyak 344 citra batik, 45 citra batik Karawang, 299 citra batik luar Karawang mencapai nilai18,60\%. 
Ayu Ratna Juwita, Tohirin Al Mudzakir, Adi Rizky Pratama, Purwani Husodo, Rahmat

Sulaiman

Vol 6 No 1

ISSN : 2541-6995

E ISSN : 2580-5517

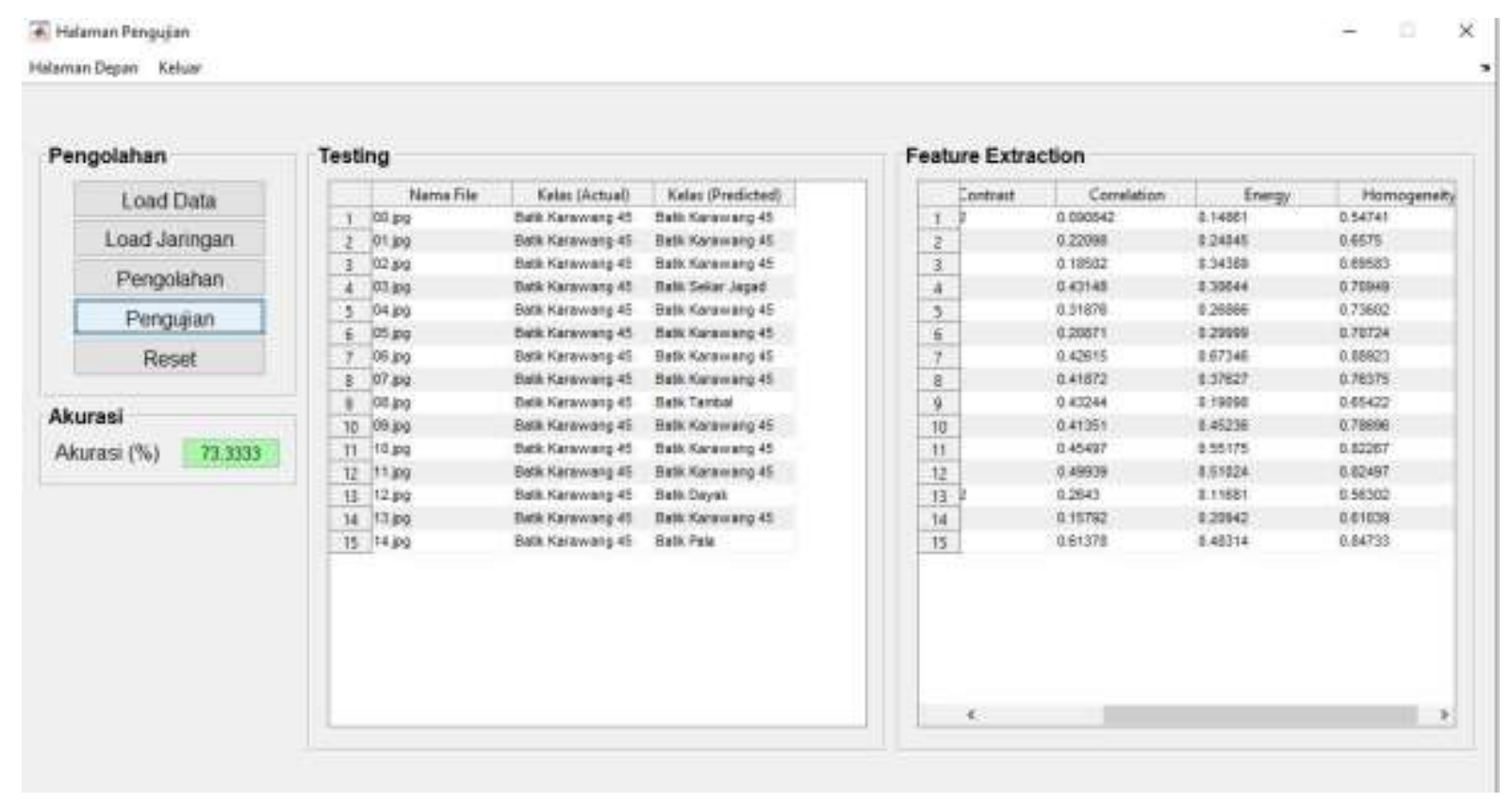

Gambar 17. Tampilan GUI saat melakukan pengujian data citra batik karawang

hasil uji coba menggunakan citra batik karawang yang dapat dikenali dan diklasifikasikan mencapai nilai tingkat akurasi 73,33\%.

6. Pengolahan citra

Proses pengolahan citra melakukan pengenalan citra batik dengan metode Convolutional Neural Network (CNN), dengan alur sebagai berikut :

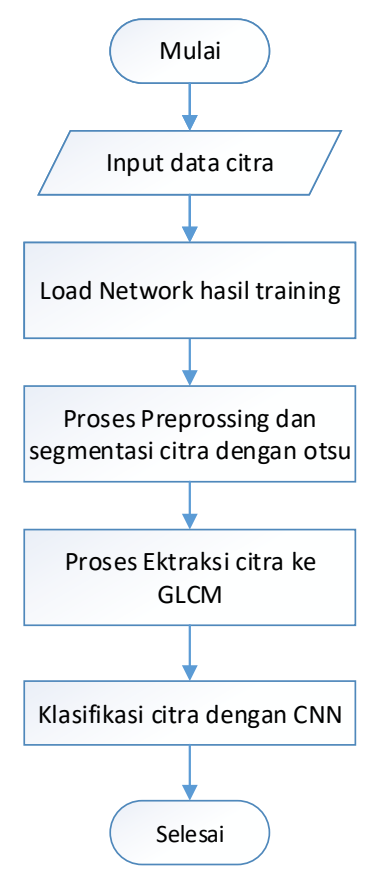

Gambar 18. Alur proses pengolahan/pengenalan citra batik 
Ayu Ratna Juwita, Tohirin Al Mudzakir, Adi Rizky Pratama, Purwani Husodo, Rahmat

Sulaiman

Vol 6 No 1

ISSN : 2541-6995

E ISSN : 2580-5517

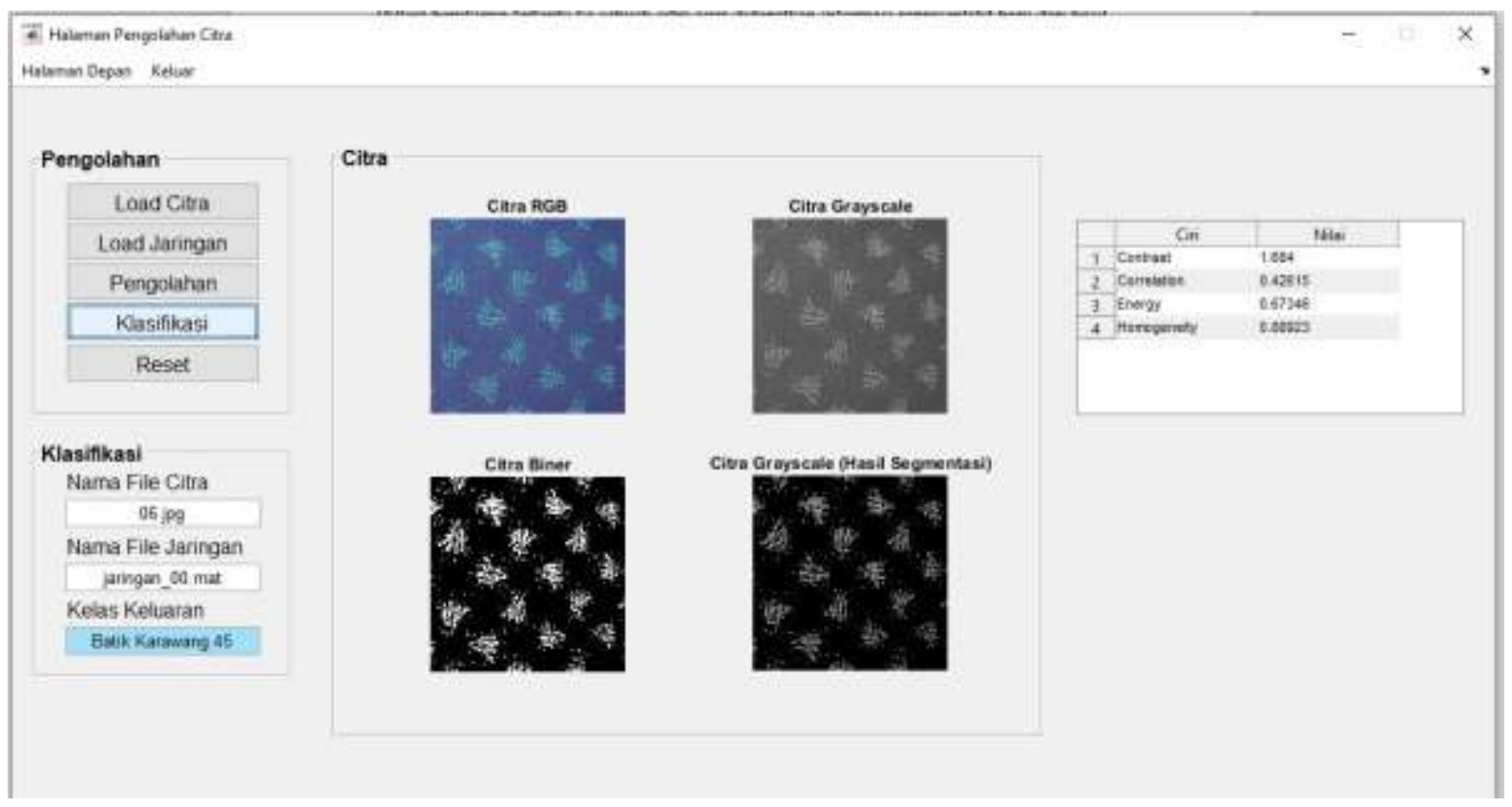

Gambar 19. Hasil GUI Pengenalan Citra Batik

Hasil dari pengolah citra batik karawang, dengan sample citra 06 dan hasilnya batik karawang 45 sehingga batik karawang dapat diidetifikasi dengan ciri Gray Level Co-occurrence Matrix (GLCM)

\section{KESIMPULAN DAN SARAN}

\section{A. KESIMPULAN}

Bedasarkan hasil pembahasan penelitian yang telah diuraikan, maka penelitian ini telah menjawab perumusan masalah penelitian sengai berikut :

1. Model sistem identifikasi batik Karawang dilakukan dengan tahapan pre-processing untuk merubah citra asli RGB menjadi grayscale, selanjutnya akan di segmentasi citra menggunakan metode otsu, ektraksi fitur-fitur citra dengan ciri GLCM (Gray Level Co-occurrence Matrix) tahap ini bertujuan untuk mendeteksi citra batik, hasil ekstraksi fitur digunakan sebagai inputan untuk diklasifikasikan dengan menggunakan Convolutional Neural Network (CNN).

2. Dalam penerapan model klasifikasi citra batik Karawang inimemliki data training sebanyak 1094 citra latih dengan nilai akurasi 18,19\% untuk citra latih, citra dapat mengklasifikasikan dengan uji coba 344 citra batik, 45 citra batik Karawang, 299 citra batik luar Karawang mencapai $18,60 \%$ nilai tingkat akurasi, sedangkan hasil 
Ayu Ratna Juwita, Tohirin Al Mudzakir, Adi Rizky Pratama, Purwani Husodo, Rahmat

uji coba menggunakan citra batik karawang yang dapat dikenali dan diklasifikasikan mencapai nilai tingkat akurasi $73,33 \%$.

\section{B. Saran}

Berdasarkan hasil penelitian dan kesimpulan yang didapat, maka saran yang dapat diberikan sebagai bahan acuan untuk penelitian selanjutnya adalah :

1. Penelitian dapat dilanjutkan dengan menggunakan proses ektrasksi selain ciri GLCM yang berbeda untuk mengukur kinerja dan tingkat akurasi sehingga didapatkan hasil terbaik untuk mengidentifikasi ciri batik.

2. Pada penelitian selanjutnya perlu adanya mempercepat waktu proses untuk mengidentifikasi gambar citra yang ber-resolusi besar lebih dari (750x750 pixel) terutama dari proses otsu.

3. Pada penelitian selanjutnya perlu dilakukan penelitian dengan melakukan pengambilan citra secara langsung, sehingga sistem bisa digunakan secara realtime.

4. Perlu dilakukan penelitian dengan pengelolaan yang disimpan pada basis data sehingga dengan data tersebut mendapatkan hasil prediksi yang lebih akurat.

\section{DAFTAR PUSTAKA}

Arisandi, Bernardinus, Nanik Suciati, and Arya Yudhi Wijaya. 2011. "Pengenalan Motif Batik Menggunakan Rotated Wavelet Filterdan Neural Network." JUTI: Jurnal Ilmiah Teknologi Informasi 9(2): 15.

Arrofiqoh, Erlyna Nour, and Harintaka Harintaka. 2018. "Implementasi Metode Convolutional Neural Network Untuk Klasifikasi Tanaman Pada Citra Resolusi Tinggi.” Geomatika 24(2): 61.

Bariyah, Taufiqotul, Mohammad Arif Rasyidi, and Ngatini Ngatini. 2021. "Convolutional Neural Network Untuk Metode Klasifikasi Multi-Label Pada Motif Batik." Techno.Com 20(1): 155-65.

Fonda, Hendry. 2020. "Klasifikasi Batik Riau Dengan Menggunakan Convolutional Neural Networks (Cnn).” Jurnal Ilmu Komputer 9(1): 7-10.

Juwita, Ayu Ratna, and Achmad Solichin. 2018. "Batik Pattern Identification Using GLCM and Artificial Neural Network Backpropagation." Proceedings of the 3rd International Conference on Informatics and Computing, ICIC 2018: 1-6.

Kuswoyo. 2015. “Analisis Visual Motif Batik Karawang (Studi Kasus Di Sentra Pengrajin Bale Batik Taza).” Analisis Visual Motif Batik Karawang (Studi Kasus di Sentra Pengrajin Bale Batik Taza). http://repository.upi.edu/19353/2/S_PSR_1102476_Abstract.pdf.

Mawan, Rizki. 2020. "Klasifikasi Motif Batik Menggunakan Convolutional Neural Network." Jnanaloka: 45-50. 
Ayu Ratna Juwita, Tohirin Al Mudzakir, Adi Rizky Pratama, Purwani Husodo, Rahmat

Sulaiman

Vol 6 No 1

ISSN : 2541-6995

E ISSN : 2580-5517

Mulaab. 2010. "Ekstraksi Fitur Motif Batik Berbasis Metode Statistik Tingkat Tinggi." Pros. Semin. Nas. Inform. UPN Veteran Yogyakarta: 69-75.

Triana, N. Neni, and Rieke Retnosary. 2020. "Pengembangan Model Pemasaran Batik Karawang Sebagai Produk Unggulan Daerah." Jurnal Inovasi dan Pengelolaan Laboratorium 2(1): 21-27. http://ejournal.uin-suka.ac.id/pusat/jipel/article/view/2075. 